\title{
An Overview of Oral Medicine and Radiology
}

\section{Tarun Vyas}

Assistant professor, Department of Oral Medicine and Radiology, R. R. Dental College and Hospital, Udaipur, India.

Review Article

Address for Correspondence Author

Dr. Tarun Vyas; Department of Oral Medicine and Radiology, R. R. Dental College and Hospital, Udaipur, India.

E-mail: tarunvyas14@gmail.com

Crossref doi: https://doi.org/10.36437/ijdrd.2020.2.3.C

\section{ABSTRACT}

Although oral medicine and radiology are speciality in many parts of the world it however 33 countries and 22 have post-graduate in oral medicine and radiology as speciality. Oral medicine is the speciality concerned with 'dental' and medical-related disorders of the oral and the facial region, including orofacial manifestations of systemic diseases. The latter include gastrointestinal, dermatological, rheumatological and haematological diseases, autoimmune and immunodeficiency disorders, and the manifestations of neurological or psychiatric disease. This review discusses the formation and growth of this oral medicine and radiology in India.

Keywords: Oral Medicine, Oral radiology, Dentistry.

Introduction: Oral medicine is a dental specialty that bridges the traditional areas of health between dentistry and medicine. International descriptions reflect this and oral medicine is defined as "the dental speciality placed at the interface between medicine and dentistry and is concerned with the diagnosis and management of (non-dental) pathology affecting the oral and maxillofacial region."1. Only recently has Oral Medicine been recognized as a specialty through the newly formed American Board of Dental Specialties (ABDS) in U.S. ${ }^{2}$ As defined by the American Dental Association, Oral and Maxillofacial Radiology is the specialty of dentistry and discipline of radiology concerned with production and interpretation of images and data produced by all modalities of radiant energy that are used for the diagnosis and management of diseases. ${ }^{3}$

History: Oral medicine specialists play a major role in the early diagnosis and treatment of various oral diseases. The history of oral medicine traces back to the $18^{\text {th }}$ century. Sir Jonathan Hutchinson, a surgeon at the London Hospital, is regarded as the father of oral medicine. In 1920s Dr. William Geis of Columbia University, United States of America established oral medicine as a distinct area of study. Overall, India was noted to have the largest increase in the number of oral medicine services as defined by increasing numbers of clinicians within the specialty as compared with other countries. Oral medicine as a subject in the curriculum of Bachelor of Dental Surgery in India has introduced around 50 years ago. Government Dental College, Bangalore was the first dental college in India to teach oral medicine with help from the World Health Organisation WHO. Government Dental College, Bangalore was also the first to introduce the Master in Dental Surgery (MDS) 2year duration course in oral medicine, diagnosis, and radiology 1970. Therefore Indian Academy of Oral 
Medicine was formed on 20th June 1985 under the guidance of Dr. BK Venkataraman and Dr. Ramachandra Reddy in Bangalore. During the Fifth National Conference held in Chennai, the academy was renamed as the Indian Academy of Oral Medicine and Radiology. Presently, the Academy has over 2500 life member4. This paper tries to put forth the challenges being faced by the specialist and suggests a pathway for future research in this field.

Oral Medicine: However, there seems to be little awareness among the medical practitioners regarding the expertise and availability of specialists in Oral Medicine and Radiology. Very few referrals of oral mucosal lesions are done to the dentists, as a majority of them are done to general dental practitioners rather than to an Oral Medicine and Radiology specialist ${ }^{5}$.

Oral Cancer: Oral cancer is of major concern as it is southeast Asia primarily because of the prevalent oral habits of betel quid chewing, smoking, and alcohol consumption. The detection, diagnosis, and management of oral diseases are complex. Refinements and continued research will undoubtedly improve our ability to detect any disease at the earliest possible stage. ${ }^{6}$ The data related to prevalence and incidence of potentially malignant (PML) and malignant lesions of the oral cavity is anybody's guess. The following could be included in the objectives for improvement in future.

1. Calculating the population-based data for incidence and prevalence of potentially malignant lesions of the oral cavity and oral malignancies. Dental schools all over India may be asked to adopt specified areas of the country to conduct a survey in a fashion similar to recently concluded National Mental Health Survey conducted by National Institute of Mental Health and Neuroscience ${ }^{7}$.

2. Application of Oral CDx Brush Biopsy in Oral Cancer Detection and bidi smokers show higher cellular proliferation as compared to non-smokers, which is similar to results obtained for cigarette smokers. However, it is not clear whether bidi smokers are at a greater risk of malignant transformation to OSCC than cigarette smokers. Further long-term studies which include large sample sizes comparing bidi and cigarette smokers need to be carried out to determine this. ${ }^{8,9}$

\section{Autoimmune Disorders Affecting Oral Cavity}

Oral non-microbial origin ulcerative and vesiculobullous lesions have mostly been treated with either steroids or immune-modulators for a long time. A standard protocol on the hierarchy of choice and usage of these drugs has not evolved yet. A Cochrane review published in the year 2011 found no randomised control trials (RCT) were available as a reference which compared the use of steroids/or other interventions with that of placebo for treatment of Lichen Planus or Oral lichenoid reactions. Similar has been the condition of other diseases of autoimmune origin of oral cavity.10,11

Forensic: The word forensic is derived from the Latin forensic, which means 'before the forum'. According to Jones, in ancient Rome, the forum was where trials and debates took place and consequently served as a court of law. On the other hands, odontology refers to the study of teeth or dentistry. Forensic odontology, therefore, has been defined by the Federation Dentaire Internationale (FDI) as "that branch of dentistry which, in the interest of justice, deals with the proper handling and examination of dental evidence and with the proper evaluation and presentation of dental findings. ${ }^{12}$ Dental and craniofacial radiographs are an important assessment tool in a race, gender, and stature due to diversity in human physical constitutional makeup. With the recent advancement of technique such as CT, Micro CT, MRI, and OPG, CBCT also aids in forensic odontology. ${ }^{13}$

\section{Systematic Profiling of Adverse/Side Effects of Medications on Oral Cavity}

$$
10 \text { International Journal of Drug Research and Dental Science }
$$


The existence of drug-induced salivary gland disorders is an accepted fact by all of us. But a recently published systematic review, by the members of World Workshop on Oral Medicine VI (WWOM VI) on medicationinduced salivary gland diseases revealed there is very minimal high-quality evidence on the effect of drugs on Salivary glands14-15 Most of the reports of drug-induced oral manifestation either rely on patient reporting of adverse effects or information on the drug labels.

Oral Radiology: CBCT is being increasingly used for point-of-service head and neck and dentomaxillofacial imaging. This technique provides a relatively high isotropic spatial resolution of osseous structures with a reduced radiation dose compared with conventional CT scans. CBCT has often been described as the "gold standard" for imaging the oral and maxillofacial area and will no doubt become a part of the everyday life of most practices in the coming decades. ${ }^{16}$

\section{Dental Management of Medically Compromised and Geriatric Patients ${ }^{4,17}$}

With an increase in life expectancy as well as improved medical health care facilities, the number of ambulatory patients with medically compromised status-seeking dental care has also increased. The multidisciplinary approach towards this problem led to a steady improvement in its end results. There is a dearth of experts in dealing with the following aspects of patient care.

- Active management of dental issues in an out-patient setting

- Management of patients as part of team managing medically compromised at a hospital in-patient setting

- Palliative management of dental issues in terminally ill patients

Conclusion: Oral medicine and radiology are the mother branch of dentistry in which deals with the diagnosis and treatment of various our diseases. In conclusion, together we need to develop a proper strategy to promote the clinical practice and theory of oral medicine amongst patients and all other healthcare professionals to increase awareness of the specialty. Thus, encourage the potential dentists to opt for the specialty which will be in the near future a boon to diagnosis. Oral medicine and radiology are for those who have an academic bent of mind and who further wish to undertake research in this speciality for furthering the growth of oral medicine and radiology.

\section{References}

1. Schmidt-Westhausen, A M, and M M Bornstein. "Orale Medizin: Interdisziplinäre Zusammenarbeit zwischen Medizin und Zahnmedizin" [Oral medicine: a specialty placed between medicine and dentistry]. Bundesgesundheitsblatt, Gesundheitsforschung, Gesundheitsschutz vol. 54, 9 (2011): 1061-5. doi: https://doi.org/10.1007/s00103-011-1329-7

2. Scully, Crispian et al. "Oral medicine (stomatology) across the globe: birth, growth, and future." Oral surgery, oral medicine, oral pathology and oral radiology vol. 121, 2 (2016): 149-157.e5. doi: 10.1016/j.oooo.2015.10.009

3. White SC, Pharoah MJ. Oral Radiology Principles and interpretation. 5th edn, 2004, p IX

4. Shetty, Shishir Ram, Mansib M. Shaik, and Subhas G. Babu. "Oral medicine and radiology-the Indian scenario." Journal of Contemporary Medical Education 1.1 (2013): 59-61.

5. Aditya, Amita, Shailesh Lele, and Priyam Aditya. "Need and availability of dentists and specialists in oral medicine and radiology: A survey." Journal of Indian Academy of Oral Medicine and Radiology 26.2 (2014): 158. 
6. Vyas, Tarun, Parnika Kuthiala, and Pradeep Vishnoi. "Oral cancer: Etiology and Its diagnostic aids." International Journal of Drug Research and Dental Science 1.2 (2019): 13-18. https://doi.org/10.36437/ijdrd.2019.1.2.G

7. Gururaj G, Varghese M, Benegal V, Rao GN, Pathak K, Singh LK, Mehta RY,Ram D, Shibukumar TM, Kokane A, Lenin Singh RK, Chavan BS, Sharma P, Ramasubramanian C, Dalal PK, Saha PK, Deuri SP, Giri AK, Kavishvar AB, Sinha VK, Thavody J, Chatterji R, Akoijam BS, Das S, Kashyap A, Ragavan VS, Singh SK, Misra R and NMHS collaborators group. National Mental Health Survey of India, 2015-16: Summary. Bengaluru, National Institute of Mental Health and Neuro Sciences, NIMHANS Publication No. 128, 2016.

8. Satish B, Tarun V. Application of oral CDx brush biopsy in oral cancer detection. J Dent Res Prac 2019; 1:4-6.

9. Vyas, Tarun et al. "Quantitative analysis of AgNOR counts and pap stain in exfoliative cytology specimens of oral mucosa in bidi smokers and nonsmokers." Annals of African medicine vol. 17, 4 (2018): 210-214. doi: 10.4103/aam.aam_69_17

10. Thongprasom K, Carrozzo M, Furness S, Lodi G. Interventions for treating oral lichen planus. Cochrane Database of Systematic Reviews 2011, Issue 7. Art. No.: CD001168. DOI: 10.1002/14651858.CD001168.pub.

11. McMillan R, Taylor J, Shephard M, Ahmed R, Carrozzo M, Setterfield J, Grando S, Mignogna M, KutenShorrer M, Musbah T, Elia A, McGowan R, Kerr AR, Greenberg MS, Hodgson T, Sirois D.World Workshop on Oral Medicine VI: a systematic review of the treatment of mucocutaneous pemphigus vulgaris. Oral Surg Oral Med Oral Pathol Oral Radiol. 2015; 120(2):132-42.e61.

12. Vyas, Tarun. "Forensic Odontology: An Overview." International Journal Of Drug Research And Dental Science 2.2 (2020): 1-2.

13. Vyas T. Radiographic determination: An upcoming aid in forensic radiology. J Int Clin Dent Res Organ 2019; 11:71-5.

14. Wolff A, Joshi RK, Ekström J, Aframian D, Pedersen AM, Proctor G, Narayana N, Villa A, Sia YW, Aliko A, McGowan R, Kerr AR, Jensen SB, Vissink A, Dawes C. A Guide to Medications Inducing Salivary Gland Dysfunction, Xerostomia, and Subjective Sialorrhea: A Systematic Review Sponsored by the World Workshop on Oral Medicine VI Drugs R D. 2017; 17(1):1-28.

15. Villa A, Wolff A, Aframian D, Vissink A, Ekström J, Proctor G, McGowan R, Narayana N, Aliko A, Sia YW, Joshi RK, Jensen SB, Kerr AR, Dawes C, Pedersen AM. World Workshop on Oral Medicine VI: a systematic review of medication induced salivary gland dysfunction: prevalence, diagnosis, and treatment. Clin Oral Investig. 2015; 19(7):1563-80.

16. Vyas T. Applications of CBCT in special reference to dentistry. J Adv Med Dent Scie Res 2017;5 (4):67-76.. doi: 10.21276/jamdsr.2017.5.4.15.

17. Vyas, Tarun, et al. "Cleft of lip and palate: A review." Journal of Family Medicine and Primary Care 9.6 (2020): 2621. doi: 10.4103/jfmpc.jfmpc_472_20.

How to cite this Article: Dr. Tarun Vyas: An Overview of Oral Medicine and Radiology

Int. J. Drug Res. Dental Sci., 2020; 2(3):9-12.

Crossref doi: https://doi.org/10.36437/ijdrd.2020.2.3.C

Source of Support: Nil, Conflict of Interest: Nil.

Received: 15-6-2020 Revised: 21-7-2020 Accepted: 26-7-2020 